\title{
0223 DECREASED ROAD TRAFFIC INJURIES MORTALITY IN IRAN - ROLE OF HEALTH SECTOR
}

S A Hassani, G Masoumi, M Fathi, M Haddadi*, M Siahtir, A Rezaee, M Khaledi Correspondence: Ministry of Health \& Medical Education, No 1, Modir alley, Monshi(Satari)Street, Africa Blvd, Tehran, Iran

10.1136/ip.2010.029215.223

Background This cross sectional study was carried in the EOC of Ministry of Health \& Medical Education, for road traffic injuries. The aim of this study was showing the role of health sector in decreasing road traffic injuries mortality as a public health challenge according to the forth developmental agenda.

Materials and Methods The data were gathered in the Disaster and Emergency Management Centres of 41 medical universities in Iran and was analyzed in the Eoc of Ministry of Health using SPSS version 12.

Result Increasing the number of prehospital emergency centres per population (25\% in 2006 comparing to 2005, and $21 \%$ in 2007 comparing to 2006), decrease in the number of death per fatal crashes (4 in 2006, in comparison with 1.3 in 2007), $43.1 \%$ decrease in the number of death at the scene and $33.8 \%$ decrease in the number of death during hospital transit in 2007 in comparison to 2005, and decrease in arrival time of EMS from $10 \mathrm{~min}$ for urban missions in 2005 to $7 \mathrm{~min}$ in 2007 all are due to five basic managerial achievements in the Ministry of Health \& Medical Education including planning, organising, staffing, leadership and control.

Conclusion For decreasing road traffic injuries mortality and morbidity rate, holistic approach in the EMS management is needed, which target both human resources (staff and training) and physical resources (infrastructure, equipment and supplies). 